\title{
Peribronchial Cuffing
}

National Cancer Institute

\section{Source}

National Cancer Institute. Peribronchial Cuffing. NCI Thesaurus. Code C124060.

A radiologic finding that describes haziness around a bronchus or large bronchiole seen

end on. It may either represent bronchial wall thickening or fluid around the bronchi. 